\title{
CARCINOMA DE CÉLULAS TRANSICIONAIS DO TRATO URINÁRIO: ASPECTOS DA TOMOGRAFIA COMPUTADORIZADA*
}

\author{
José Guiomar de Almeida Junior ${ }^{1}$, Maria Lúcia de Oliveira Santos ${ }^{2}$, Telmo Pimentel do Vabo², \\ Klezer Gaspar Carvalho da Silva ${ }^{3}$, Alessandro Severo Alves de Melo ${ }^{4}$, Luiza Beatriz Melo \\ Moreira $^{4}$, Maria Angélica Soares Muniz ${ }^{4}$, Alexandre Szerman ${ }^{5}$, Edson Marchiori ${ }^{6}$
}

Resumo Embora relativamente incomum, o carcinoma de células transicionais do trato urinário é o segundo tumor mais freqüente do rim. Neste trabalho foram analisadas, de forma retrospectiva, as tomografias computadorizadas de dez pacientes com carcinoma de células transicionais confirmado por exame histopatológico. A bexiga foi acometida em $60 \%$ dos casos, o sistema pielocalicinal em $60 \%$ e o ureter em $10 \%$ deles. Lesões sincrônicas estiveram presentes em $\mathbf{4 0 \%}$ das vezes. Os aspectos encontrados foram lesões vegetantes, espessamento da parede do ureter e lesões infiltrativas do rim. Foram descritos dois casos de tumores calcificados e um carcinoma de células transicionais surgindo no interior de um divertículo de bexiga. A tomografia computadorizada detectou extensão local do tumor em $80 \%$ dos pacientes e lesão a distância em 20\%. A tomografia computadorizada permitiu caracterizar a extensão da doença, localmente e a distância, possibilitando que um grupo selecionado de pacientes pudesse ser tratado de forma conservadora.

Unitermos: Carcinoma de células transicionais; Tomografia computadorizada; Tumores renais.

Abstract Transitional cell carcinoma of the urinary tract: computed tomography findings.

Although rare, transitional cell carcinoma of the urinary tract is the second most common tumor of the kidneys. We studied retrospectively the computed tomography images of 10 patients with confirmed transitional cell carcinoma of the urinary tract. There was involvement of the bladder in $60 \%$ of the cases whereas the calyceal system and the ureters were involved in $60 \%$ and $10 \%$ of the cases, respectively. Concomitant tumors were present in $\mathbf{4 0} \%$ of the cases. The findings were sessile masses, ureteral wall thickening and renal infiltrative lesions. Calcified tumors were seen in two patients and a transitional cell tumor arising from a bladder diverticulum was identified in another patient. Local tumor dissemination was observed in $80 \%$ of the patients and distant dissemination in $20 \%$ of the patients. Computed tomography allowed the detection of local and distant tumor dissemination, thus allowing a selected group of patients to be treated conservatively.

Key words: Transitional cell carcinoma; Computed tomography; Renal tumors.

\section{INTRODUÇÃO}

Os carcinomas de células transicionais (CCT) correspondem a cerca de $90 \%$ dos tumores do uroepitélio. Os demais tumores, na sua grande maioria, são carcinomas

* Trabalho realizado no Departamento de Radiologia da Universidade Federal Fluminense (UFF), Niterói, RJ, no Senviço de Radiodiagnóstico do Hospital Universitário Clementino Fraga FiIho (HUCFF) da Universidade Federal do Rio de Janeiro (UFRJ) Rio de Janeiro, RJ, e no Serviço de Radiodiagnóstico do Hospital de Clínicas de Niterói.

1. Médico Pós-graduando do Departamento de Radiologia da UFF.

2. Professores Adjuntos de Radiologia da UFF, Médicos Radiologistas do Hospital de Clínicas de Niterói.

3. Médico Urologista do Hospital de Clínicas de Niterói e do Hospital dos Servidores do Estado.

4. Médicos Radiologistas do Hospital de Clínicas de Niterói, Mestres em Radiologia pela UFRJ.

5. Mestrando em Radiologia pela UFRJ.

6. Professor Titular de Radiologia da UFF, Coordenador Adjunto do Curso de Pós-Graduação em Radiologia da UFRJ.

Endereço para correspondência: Prof. Dr. Edson Marchiori. Rua Thomaz Cameron, 438, Valparaíso. Petrópolis, RJ, 25685-120. E-mail: edmarchiori@zipmail.com.br

Recebido para publicação em 22/8/2002. Aceito, após revisão, em 7/10/2002. epidermóides (em torno de 10\%), e menos de $1 \%$ são adenocarcinomas ${ }^{(1)}$. Esses tumores são freqüentemente multicêntricos, tendendo a ser localmente invasivos. Um grande número de substâncias pode estar relacionado ao desenvolvimento dos tumores uroepiteliais ${ }^{(2)}$.

No passado, a avaliação pré-operatória da extensão da doença tinha valor limitado, já que quase todos os pacientes eram tratados com nefroureterectomia. Mais recentemente, vários estudos têm mostrado que em alguns pacientes com doença localizada a ressecção limitada pode ser igualmente efetiva ${ }^{(2,3)}$.

Os métodos de imagem convencionais, como a urografia excretora e a pielografia retrógrada, são úteis na localização das lesões, mas em geral não são capazes de detectar a extensão do tumor ou a presença de metástases linfonodais ${ }^{(2)}$. Dessa forma, a tomografia computadorizada (TC) é de grande utilidade, sendo os padrões mais comuns as falhas de enchimento ureteropielocalicianas ou vesicais, irregularidade focal do uroepitélio, estenose infundibular e cálices distendidos ou amputados ${ }^{(\mathbf{1})}$.

Neste trabalho foram revisados os achados tomográficos de dez pacientes com CCT comprovado do trato urinário.

\section{CASUÍSTICA E MÉTODOS}

Foi realizado estudo retrospectivo das TCs de dez pacientes com CCT do trato urinário confirmado por estudo histopatológico. Os pacientes foram todos provenientes de instituições do Rio de Janeiro.

Os exames foram realizados em tomógrafos diferentes, devido à multiplicidade de instituições de origem dos casos. Os pacientes foram estudados com as rotinas próprias de cada serviço, sendo feitos cortes da cúpula diafragmática até a sínfise 
púbica. Todos os pacientes foram examinados antes e após a infusão venosa do meio de contraste iodado, e cinco deles receberam contraste iodado via oral. O registro foi feito em filme radiológico, com janelas variando entre 162 e 500 unidades Hounsfield (UH) e níveis entre 7 e 70 UH.

$\mathrm{Na}$ análise das TCs os aspectos estudados foram: a localização do tumor no trato urinário, sua multicentricidade, a presença de calcificações, sua impregnação pelo meio de contraste iodado, e extensão local e a disseminação a distância. A impregnação pelo meio de contraste iodado foi classificada como significativa (> 15 $\mathrm{UH})$ ou não significativa (< $15 \mathrm{UH})$.

\section{RESULTADOS}

Dos dez pacientes estudados, seis eram do sexo masculino (60\%) e quatro eram do sexo feminino (40\%). A idade variou de 39 a 78 anos, com média de 63 anos.

Tumores sincrônicos foram observados em quatro dos casos (40\%) (Figura 1). Nesses quatro casos de tumores sincrônicos o sistema pielocalicinal estava acometido, um deles com lesão conjunta no ureter, es- pessando-o, e os três restantes com lesões na bexiga. $\mathrm{O}$ tumor se apresentou como lesão única em seis dos pacientes (50\%), em três destes acometendo o sistema pielocalicinal e nos outros três, a bexiga.

Sete pacientes tinham acometimento do sistema pielocalicinal, que se apresentou como lesões vegetantes em cinco deles (Figura 2A), e nos outros dois, como lesões infiltrativas do rim (Figura 2B).

Dos seis pacientes com doença vesical, cinco apresentavam lesões vegetantes, estando quatro localizadas no soalho, próximo ao trígono, determinando obliteração

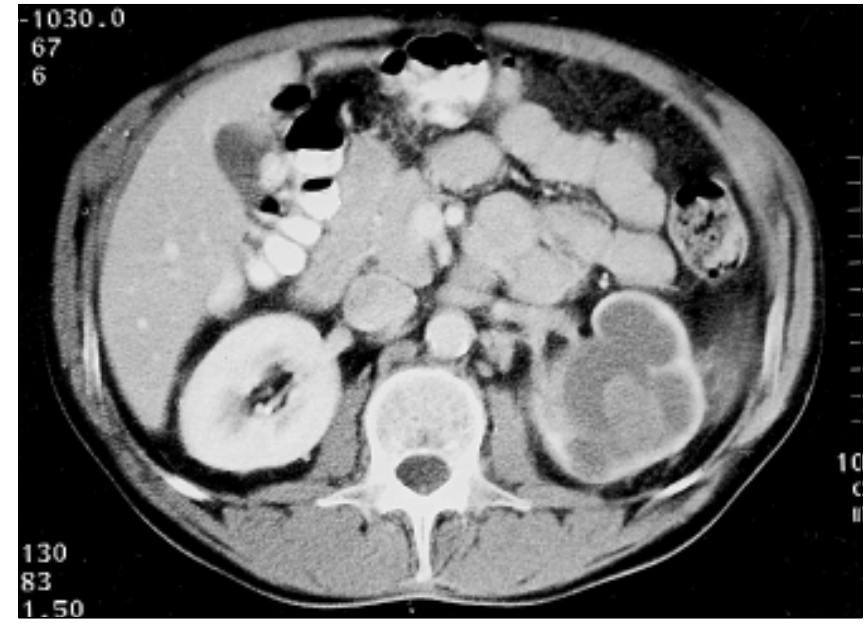

A

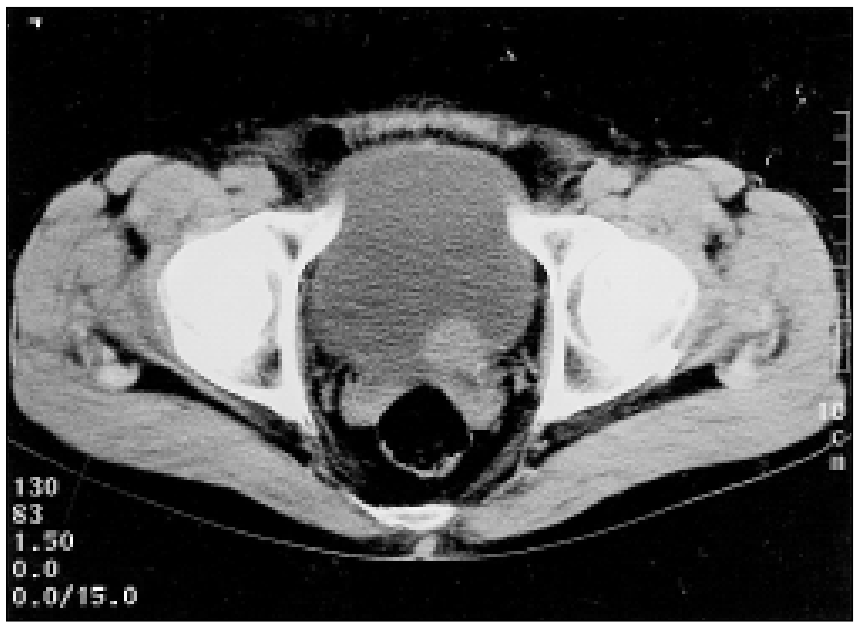

Figura 1. Tomografias computadorizadas do abdome e pelve na fase portal, em que se observa vegetação no interior do sistema pielocalicinal esquerdo, que se impregnou significativamente pelo meio de contraste iodado $(\mathbf{A})$. Na bexiga $(\mathbf{B})$ nota-se vegetação ao nível do óstio ureteral do mesmo lado, demonstrando tratarse de um carcinoma de células transicionais sincrônico.

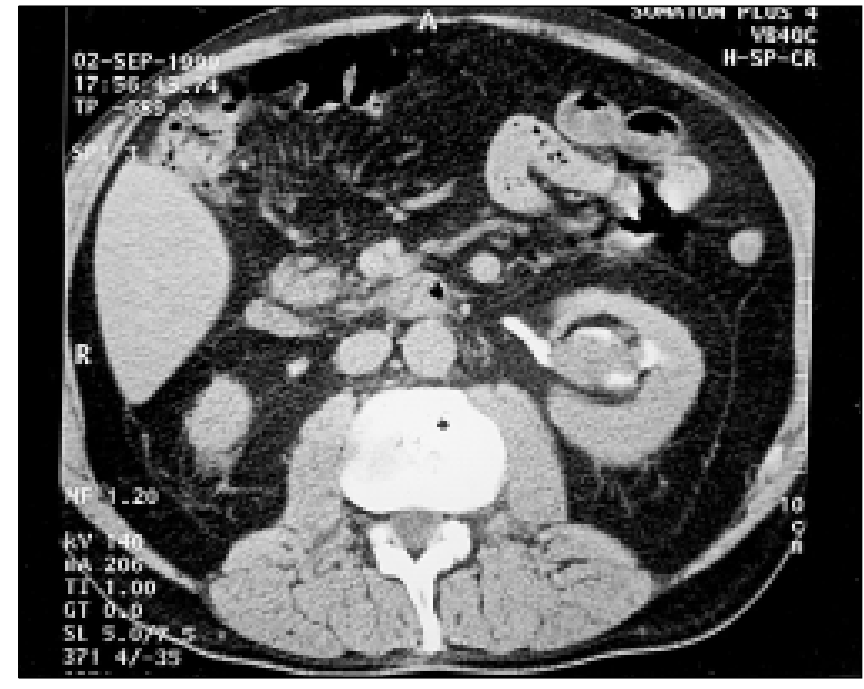

A

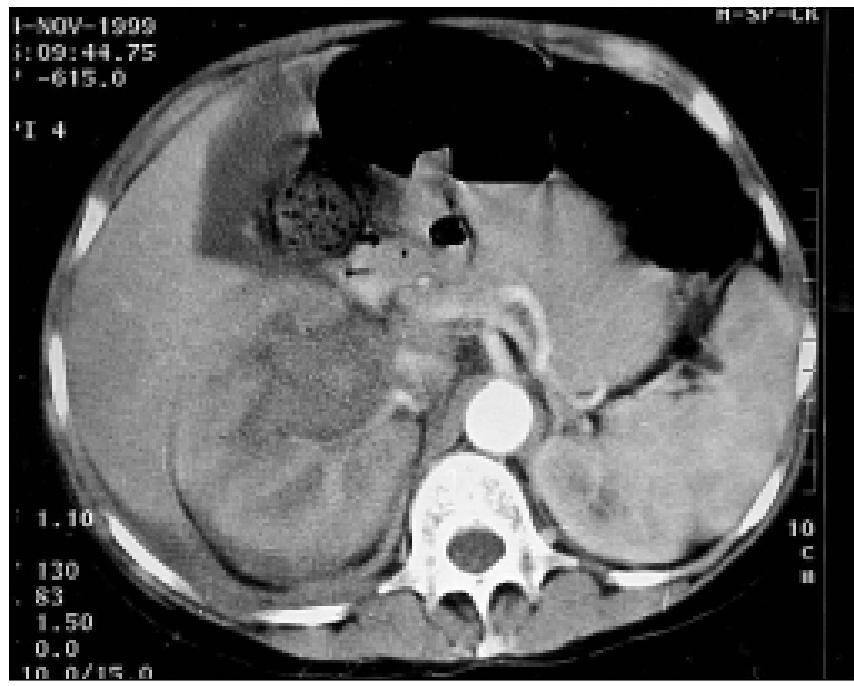

B

Figura 2. Tomografias computadorizadas do abdome de dois pacientes diferentes mostrando, em $\mathbf{A}$, falha de enchimento com densidade de partes moles no sistema pielocalicinal esquerdo determinando distensão da pelve e amputação de cálices. Em $\mathbf{B}$ observa-se o sistema pielocalicinal direito ocupado por massa com densidade de partes moles, que infiltra o rim e determina aumento do volume com presenvação do contorno renal. 
do meato ureterovesical e dilatação a montante (Figuras 3 e 4), e uma outra surgindo no interior de um divertículo (Figura 5). Em um dos pacientes o tumor se apresentou como espessamento circunferencial acentuado da parede vesical.

Nos casos em que a densidade foi medida (três pacientes), ela variou de 14,7 a 30,8 UH, com impregnação pelo meio de contraste variando de 16,3 a 51,3 UH (média de 29,1 UH) (Figura 6).
Lesões calcificadas foram observadas em dois pacientes, um deles com calcificações granulares no sistema pielocalicinal (Figura 7) e outro com calcificação linear na superfície mucosa da bexiga. Em oito pacientes a TC detectou densificação da gordura perivesical e/ou perirrenal (Figura 8), e em dois casos ficou demonstrada a disseminação a distância do tumor por via hematogênica, uma com destruição do sacro e outra do ilíaco (Figura 9).

\section{DISCUSSÃO}

Embora seja relativamente incomum, o CCT é o segundo tumor maligno mais freqüente do rim, correspondendo a $7 \%$ a $10 \%$ dos tumores deste órgão ${ }^{(4)}$. A hematúria macroscópica indolor habitualmente é a manifestação clínica inicial; no entanto, ela pode estar ausente em $20 \%$ a $30 \%$ dos casos, o que retarda o diagnóstico ${ }^{(4)}$. O tumor pode ser demonstrado pela ultra-

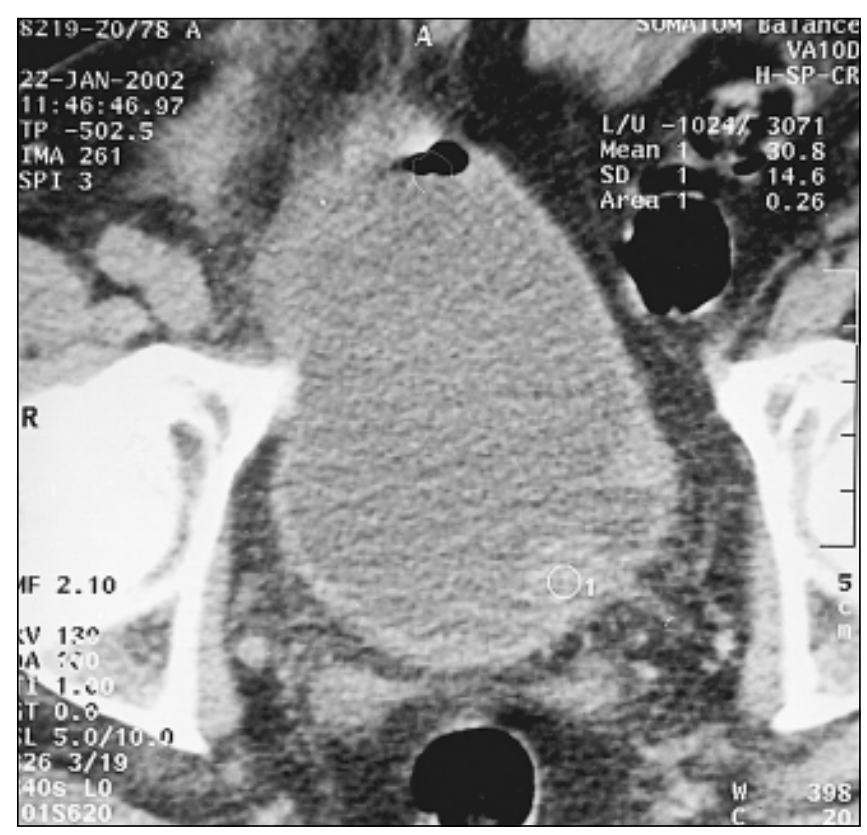

A

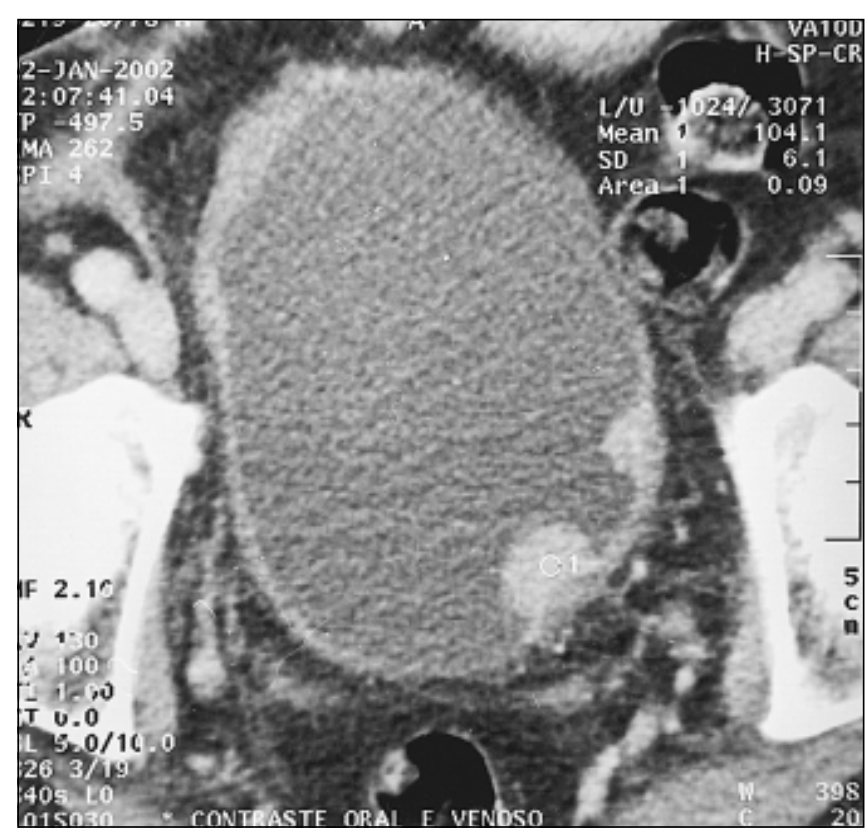

B

Figura 3. Cortes axiais ampliados da bexiga mostrando lesões vegetantes junto ao óstio ureterovesical esquerdo que se impregnaram significativamente pelo meio de contraste iodado. Observam-se, também, espessamento da parede súpero-lateral direita da bexiga e densificação da gordura perivesical.

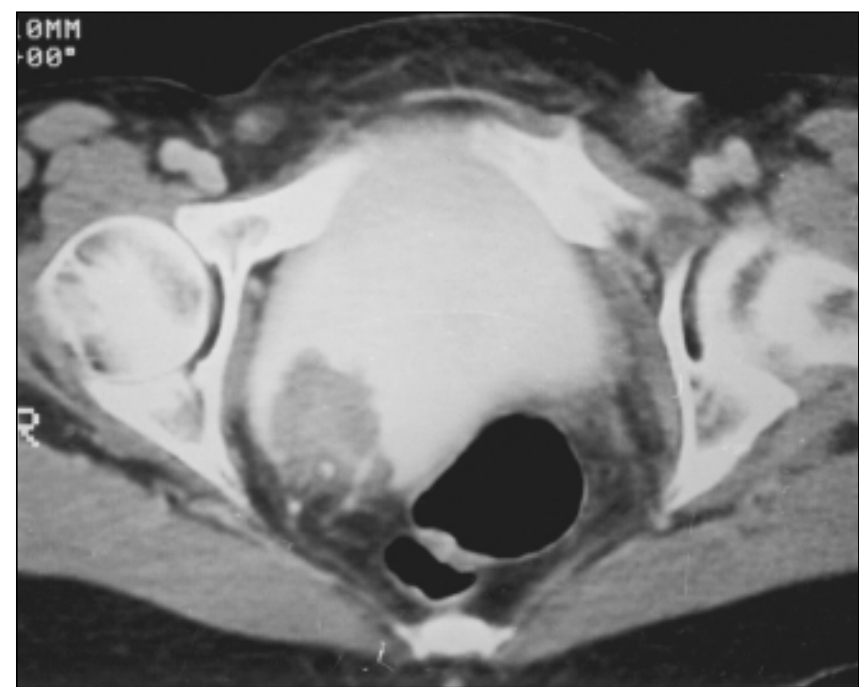

Figura 4. Tomografia computadorizada na fase excretora demonstrando falha de enchimento vegetante junto ao óstio ureterovesical direito, com infiltração do soalho vesical e densificação da gordura adjacente.

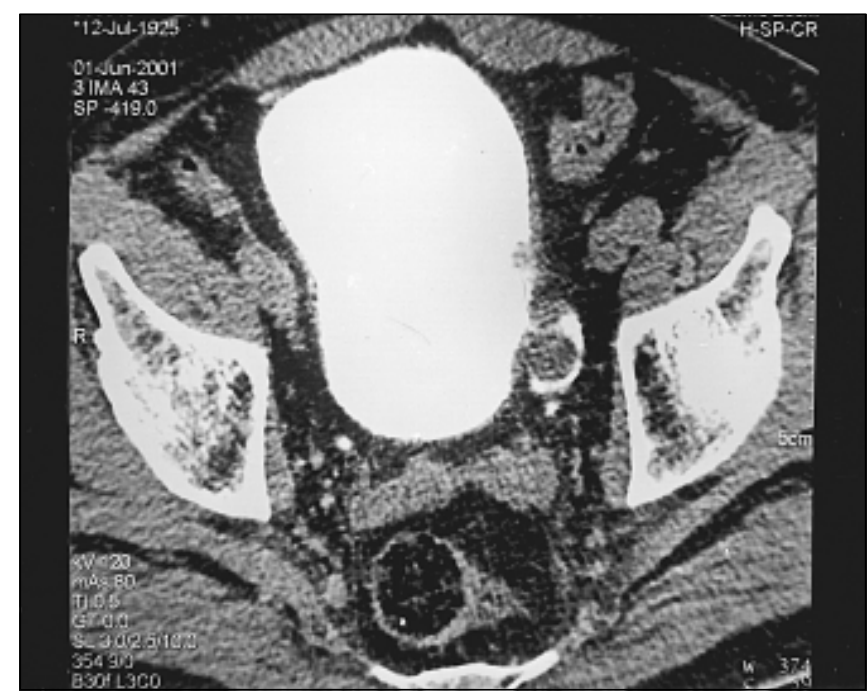

Figura 5. Corte axial ampliado da bexiga na fase excretora, na qual se observa falha de enchimento no interior de um divertículo, que correspondeu a um carcinoma de células transicionais. 


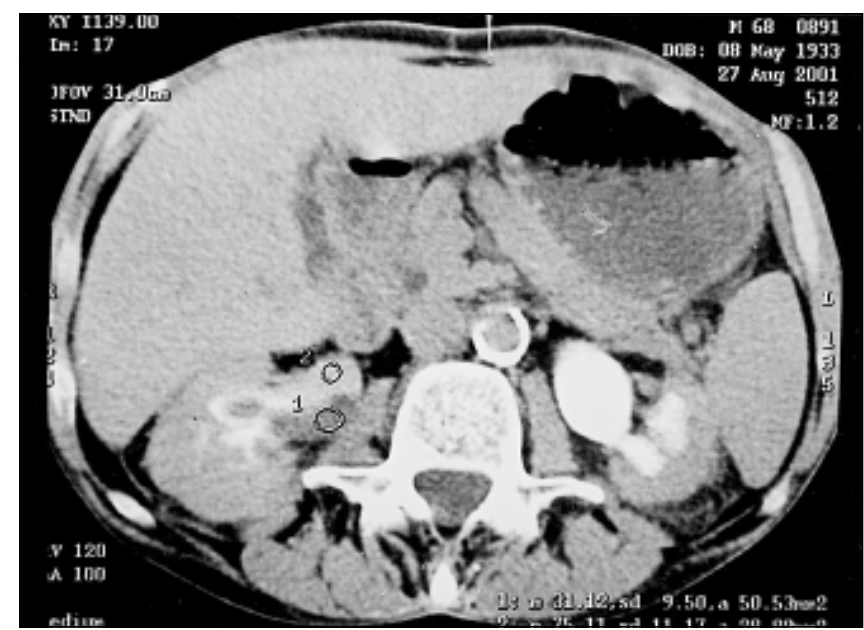

Figura 6. Tomografia computadorizada do abdome na fase excretora, com a presença de falhas de enchimento no sistema pielocalicinal direito que se impregnaram significativamente pelo meio de contraste iodado.

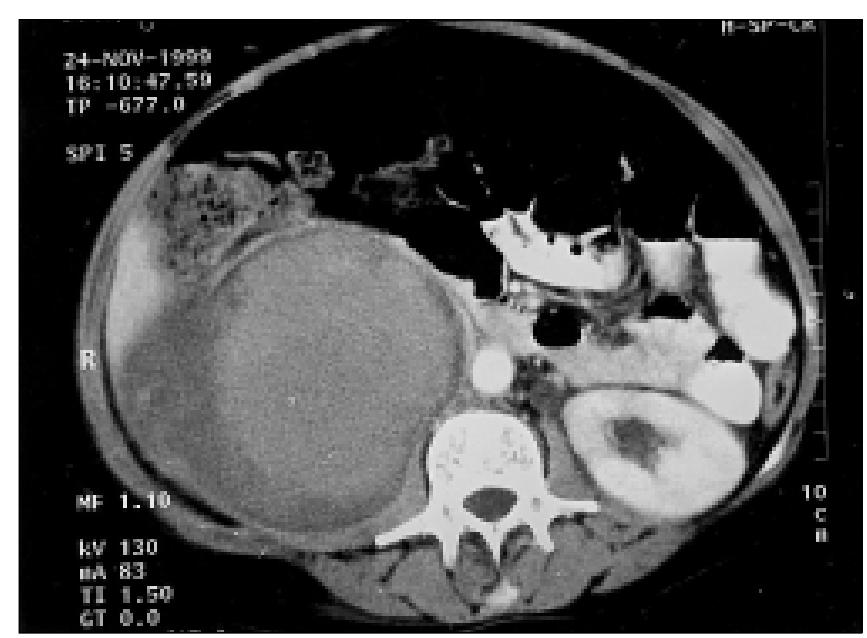

Figura 8. Tomografia computadorizada do abdome evidenciando massa do sistema pielocalicinal direito que infiltra o parênquima renal, a gordura perirrenal e a fáscia pararrenal posterior.

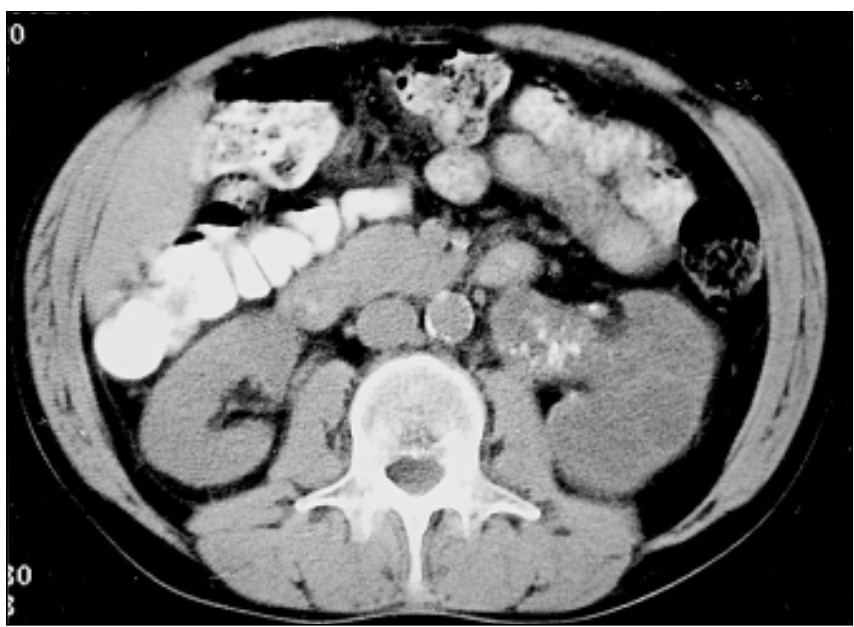

Figura 7. Tomografia computadorizada do abdome sem contraste venoso demonstrando lesões vegetantes no sistema pielocalicinal esquerdo e áreas de calcificação granular na pelve renal.

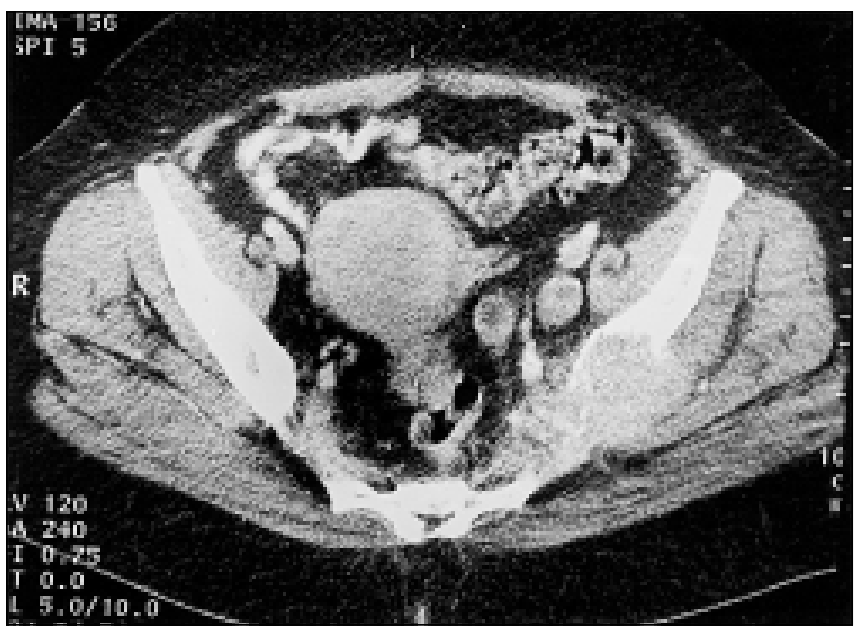

Figura 9. Corte axial da pelve evidenciando lesão lítica no ilíaco esquerdo, com massa de partes moles. sonografia e por métodos radiológicos convencionais, embora a TC seja fundamental no estadiamento.

Neste estudo observou-se que o CCT acometeu pacientes entre 39 e 78 anos, com média de idade de 63 anos, achado semelhante àquele observado pela maioria dos autores $^{(\mathbf{1 , 2 , 5})}$. Nossos casos apresentaram distribuição quase igualitária entre os sexos, com pequeno predomínio do sexo masculino (60\%). Outros autores também relataram predomínio em homens, com porcentuais variando de $64,1 \%$ a $81,5 \%$ dos $\operatorname{casos}^{(\mathbf{1}, 6,7)}$.

Houve grande porcentual de sincronismo das lesões (40\%), como o descrito pela maioria dos autores ${ }^{(\mathbf{1 - 4})}$.
A bexiga foi o sítio mais comum do tumor (60\% dos casos), três dos quais como lesões isoladas e três como tumores sincrônicos. O seu maior acometimento está relacionado à maior superfície e tempo de exposição do uroepitélio às substâncias carcinogênicas $^{(\mathbf{1 , 8})}$. Apesar do relativo predomínio, o porcentual de acometimento vesical foi muito inferior ao descrito na literatura, com dados que denotam freqüência de tumor de bexiga 50 vezes maior do que o da pelve renal ${ }^{(\mathbf{1})}$

Os casos de acometimento da pelve renal e ureter possuíram padrões semelhantes aos descritos por Baron et al. ${ }^{(2)}$, que relataram três formas de apresentação do CCT da pelve renal e ureter na TC: mas- sas vegetantes, espessamento da parede ureteral e massa infiltrando o rim.

Nos três casos em que as lesões tiveram suas densidades aferidas antes e após a infusão venosa do meio de contraste iodado, encontramos densidades iniciais das lesões variando de 14,7 a 30,8 UH (média de 22,7 UH), com impregnação média de 29,1 UH, condizente com os valores descritos na literatura. Parienty et al. ${ }^{(9)}$ relataram variação de 20 a $40 \mathrm{UH}$ na sua série de 39 pacientes com CCT. Baron et al. ${ }^{(\mathbf{2})}$ descreveram valores de atenuação variando de 40 a 68 UH. Segundo Leder e Dunnick $^{(\mathbf{1})}$, os CCTs podem ser detectados como massa de densidade maior que a da urina e menor que a do parênquima renal 
(8 a 30 UH), com impregnação significativa após a infusão venosa do meio de contraste iodado (18 a $55 \mathrm{UH})$.

A medição da densidade e o padrão de impregnação permitem que esses tumores sejam diferenciados de outras causas de falha de enchimento no trato urinário (cálculos e coágulos sanguíneos) Os coágulos possuem coeficiente de atenuação que varia de 50 a $65 \mathrm{UH}$, maior que o de tecidos moles e menor que o dos cálculos renais (100 a 250 UH). Além disso, os coágulos não se impregnam pelo meio de contraste, e nos casos em que o diagnóstico diferencial se torna difícil, o seguimento tomográfico demonstra a redução progressiva das dimensões e do coeficiente de atenuação dos coágulos ${ }^{(\mathbf{9})}$.

Em um dos nossos casos houve o surgimento de um CCT no interior de um divertículo de bexiga. Dondalski et al. ${ }^{(\mathbf{8})}$ descreveram o desenvolvimento de neoplasias no interior de divertículos de bexiga em $2 \%$ a $7 \%$ dos pacientes com divertículos vesicais. Dragsted e Nilsson ${ }^{(\mathbf{1 0})}$ relataram a dificuldade da avaliação dos divertículos de bexiga de colo estreito por cistoscopia, reiterando a importância da TC na pesquisa de tumor nesses pacientes. É improvável que o divertículo seja, por si mesmo, prémaligno. No entanto, parece que a presença de divertículos aumenta a suscetibilidade da mucosa vesical à carcinogênese, talvez por funcionar como bolsões de urina estagnada ${ }^{(\mathbf{1})}$.

Em nossa série relatamos dois casos de CCT com calcificações, uma de aspecto granular em um tumor da pelve renal e outra linear nas superfícies mucosas de uma bexiga com paredes difusamente espessadas por tumor. Dinsmore et al. ${ }^{\text {(11) }}$ descreveram freqüência de $0,69 \%$ de calcificação em CCTs de bexiga. Ferris e $\mathrm{O}^{\prime}$ Connor ${ }^{(\mathbf{1 2})}$ encontraram prevalência de $6,7 \%$ de CCTs calcificados em seu estu- do. Calcificações em CCTs ocorrem por necrose, hemorragia ou degeneração cística do tumor ${ }^{(\mathbf{1 1})}$. A calcificação pode também ser influenciada por isquemia local, infecção ou pH urinário que facilita a deposição do fosfato de cálcio no tecido necrótico em urina alcalina ${ }^{(12,13)}$

No nosso estudo sete pacientes apresentavam doença avançada, caracterizada pela extensão do tumor para o parênquima renal, gordura perirrenal ou perivesical e metástases a distância (estádios III e IV). Embora a TC não possa determinar a profundidade da invasão tumoral na parede pélvica renal e vesical, pode avaliar se o tumor se estendeu além da muscular, até a gordura do seio renal e perivesical ${ }^{(\mathbf{1 4})}$. A extensão do tumor para a veia renal e veia cava inferior raramente pode ser mostrada pela $\mathrm{TC}^{(\mathbf{1 4})}$. A TC pode mostrar metástase para linfonodos regionais, embora algumas vezes subestadie tumores com linfonodos retroperitoneais centrais de tamanho nor$\mathrm{mal}^{(\mathbf{1 4})}$. A ressonância magnética (RM), apesar de não ser o exame de escolha para o diagnóstico e acompanhamento do CCT, mostra-se mais sensível que a TC na avaliação da extensão local da doença, principalmente nos casos em que os planos gordurosos se encontram minimamente in$\operatorname{vadidos}^{(\mathbf{1 , 1 4})}$. Além disso, a RM tem maior capacidade de detectar a extensão vascular da doença $a^{(1,14)}$.

Concluindo, em nosso estudo descrevemos os achados tomográficos em dez pacientes com CCT do trato urinário, encontrando aspectos semelhantes aos relatados pela literatura, o que reforça o papel do método tanto no diagnóstico como no estadiamento e seguimento dos pacientes com suspeita ou CCT confirmado. Com o estabelecimento da segurança de tratamentos conservadores em casos de doença localizada, a avaliação da extensão da doença passou a ser fundamental na seleção dos pacientes que poderiam se beneficiar de uma conduta menos agressiva.

\section{REFERÊNCIAS}

1. Leder RA, Dunnick NR. Transitional cell carcinoma of the pelvicalices and ureter. AJR 1990;155:713-22.

2. Baron RL, McClennan BL, Lee JKT, Lawson TL. Computed tomography of transitional cell carci noma of the renal pelvis and ureter. Radiology 1982;144:125-30.

3. Urban BA, Buckley J, Soyer P, Scherrer A, Fishman EK. CT appearance of transitional cell carcinoma of the renal pelvis. Part 1. Early-stage disease. AJR 1997;169:157-61.

4. Lee TY, Ko SF, Wan YL, et al. Unusual imaging presentations in renal transitional cell carcinoma. Acta Radiol 1997;38:1015-9.

5. Gatewood OMB, Goldman SM, Marshall FF, Siegelman SS. Computerized tomography in the diagnosis of transitional cell carcinoma of the kidney. J Urol 1982;127:876-87.

6. Koraitim M, Kamal B, Metwalli N, Zaky Y. Transurethral ultrasonographic assessment of bladder carcinoma: its value and limitation. J Urol 1995; 154(2 Pt 1):375-8.

7. Buckley JA, Urban BA, Soyer P, Scherrer A, Fishman EK. Transitional cell carcinoma of the renal pelvis: a retrospective look at CT staging with pathologic correlation. Radiology 1996;201:194 8.

8. Dondalski M, White EM, Ghahremani GG, Patel SK. Carcinoma arising in urinary bladder diverticula: imaging findings in six patients. AJR 1993; 161:817-20.

9. Parienty RA, Ducellier R, Pradel J, Lubrano JM, Coquille F, Richard F. Diagnostic value of CT numbers in pelvocalyceal filling defects. Radiology 1982;145:743-7.

10. Dragsted J, Nilsson T. Urothelial carcinoma in a bladder diverticulum evaluated by transurethral ultrasonography. Scand J Urol Nephrol 1985;19: $153-4$.

11. Dinsmore BJ, Pollack HM, Banner MP. Calcified transitional cell carcinoma of the renal pelvis. Radiology 1988;167:401-4.

12. Ferris EJ, O'Connor SJ. Calcification in urinary bladder tumors. Am J Roentgenol Radium Ther Nucl Med 1965;95:447-9.

13. Pollack HM, Banner MP, Martinez LO, Hodson CJ. Diagnostic considerations in urinary bladder wall calcification. AJR 1981;136:791-7.

14. Levine E. O rim. In: Haaga JR, Lanzieri CF, Sartoris DJ, Zerhouni EA, eds. Tomografia computadorizada e ressonância magnética do corpo humano. $3^{\mathrm{a}}$ ed. Rio de Janeiro, RJ: Guanabara Koogan, 1996:1048-106. 